\title{
The Impact of the Registered Intermediary on Adults' Perceptions of Child Witnesses: Evidence from a Mock Cross Examination
}

\author{
Abstract \\ Registered intermediaries are communication specialists appointed to facilitate the \\ communication of vulnerable witnesses participating in the criminal justice system in \\ England and Wales. Intermediaries assess the vulnerable individual's communication and \\ provide recommendations to practitioners for how to obtain the individual's 'best evidence' \\ during police interviews and in court. The scheme was implemented nationally in 2008, but \\ has not been subject to rigorous research. The aim of the current article is to provide an \\ account on adults' perceptions of the vulnerable individual when an intermediary assists their \\ communication in court. In the present study one hundred participants viewed a mock cross \\ examination of a child witness either with or without an intermediary present. Participants \\ rated the child's behaviour and communication, and the quality of the cross examination, \\ across a number of different variables. The age of the child was also manipulated with \\ participants viewing a cross examination of a four or a thirteen year old child. The results \\ showed the children's behaviour and the quality of the cross-examination were more highly \\ rated when the intermediary was involved during cross-examination. The older child's cross- \\ examination was rated as more developmentally appropriate, however no other age \\ differences or interactions emerged. The findings have positive implications for jury \\ perceptions of children's testimony when they are assisted by an intermediary in court, \\ regardless of the age of the child witness. The success of the intermediary scheme in \\ England and Wales may encourage the implementation of intermediaries internationally.
}


The use of intermediaries in England and Wales to facilitate the communication of vulnerable individuals is now commonplace. The witness intermediary scheme was implemented nationally in 2008 and currently on average 13 requests for intermediaries are made per day, and in the year 2014, 3332 requests were made in total. This is an increase in $81 \%$ from 2013 to 2014 (Smith, 2015). The success of the scheme is supported by the increase in the numbers of referrals since its conception and the positive comments provided by carers, and practitioners such as police officers and barristers (Plotnikoff \& Woolfson, 2007). Anecdotal information has indicated that practitioners feel more confident in their work with vulnerable witnesses due to the assistance of the intermediary. However, what is not clear is the effect the scheme has on the fairness of criminal proceedings. In particular, how the presence of the intermediary affects juror perceptions of the vulnerable witness in court (O'Mahony, 2010). In England and Wales intermediaries can be seen over the live link sitting next to the vulnerable witness whilst they are being cross examined or sitting/standing next to the witness when they are being cross examined in the courtroom. At the discretion of the judge they are also permitted to intervene during questioning if their communication recommendations for the vulnerable person are not adhered to (Ministry of Justice, 2015). Because of the possible invasiveness of the presence of the intermediary in court, it is important to consider the effect that this has on jury perceptions of the vulnerable person the intermediary is assisting.

According to legislation a witness is considered 'vulnerable' if they are under the age of 18, and/or have a mental disorder or impairment of intelligence, social functioning or physical disability/disorder (Youth, Justice and Criminal Evidence Act 1999). With regards to the empirical investigation of vulnerable witnesses, the majority of research has focused on the communication and perception of children in court (e.g. Davies, Henderson, \& Hanna, 2010; Sumner-Armstrong \& Newcombe, 2007). The importance of accommodating children's testimony has been well documented (Cossins, 2006; Davies, Devere, \& Verbitsky, 2004; Doherty-Sneddon \& McAuley, 2000; Powell, 2005). Children are stressed when providing their evidence and the accuracy of the information they produce may decrease during cross-examination (Righarts, Jack, Zajac, \& Hayre, 2015). In addition, children can change the content of their testimony even if the accuracy of the information held in memory remains intact (Righarts et al., 2015). Such inconsistencies in the victim's account can decrease the likelihood of a conviction (Berman \& Cutler, 1996). Furthermore, jury members have been found to have a negative perception of children's testimony and this can have a detrimental impact on the perceived credibility of their account (Quas, Thompson, $\&$ Clarke-Stewart, 2005). Age has proven to be a consistent indicator of witness believability, with adults and older children deemed more accurate providers of information than younger children (e.g. Holcomb \& Jacquin, 2007; Nikanora \& Ogloff, 2005; Pozzulo, Lemieux, Wells, \& McCuaig, 2006). In addition, Henry, Ridley, Perry, and Crane (2011) found the credibility of testimony from children is even further reduced in the eyes of the jury when children present with a learning disability.

In the past twenty years different measures have been implemented in courts internationally to assist the accounts of vulnerable individuals and enable them to provide their 'best evidence'. In England and Wales these are referred to as 'special measures' and include video recorded evidence in chief, testimony via live link, use of screens to shield the witness from the defendant, removal of wigs and gowns and the use of an intermediary (Youth, Justice and Criminal Evidence Act 1999). When these measures were first introduced a number of studies were produced that examined the effects of these new measures on children's communication and behaviour. Hamlyn, Phelps, Turtle, and Sattar (2004) carried out an extensive review of the measures and found that they can reduce children's feelings of anxiety and improve their experience when providing evidence. Overwhelmingly the majority of research on special measures has focused on the impact of the live link on children's testimony. Children report being less nervous and more capable of 
providing their evidence over the live link (Landstrom \& Granhag, 2010; Goodman et al., 1998; Wilson \& Davies, 1999) and a number of studies have found younger children produce more errors in response to misleading questions when communicating face to face than via live video link (Doherty-Sneddon \& McAuley, 2000; Goodman et al., 1998).

Despite these improvements, findings for juror perceptions of children testifying over the live link have been less favourable. Some research studies report no differences for jury perceptions when comparing live link versus open court testimony (Orcutt, Goodman, Tobey, Batterman-Faunce, \& Thomas, 2001; Ross, Hopkins, Hanson, Lindsay, Hazon, \& Eslinger, 1994). However, the majority demonstrate that jurors view testimony more positively and are better convinced when they observe children in court than across a video link (Landstrom \& Granhag, 2007, 2010). Jurors perceive children as less credible (Eaton, Ball, \& O'Callaghan, 2001), accurate and believable when they testify via live link and some research indicates this may affect conviction rates with a bias in favour of the defence (Goodman et al., 1998). McAuliff and Kovera (2012) propose that this bias may occur because jurors have expectations about children's behaviour and when these expectations are violated this leads to a negative perception of the child. For example, jurors expect children who testify to be nervous and less coherent. If children do not present this way, because of an improvement in demeanour as a result of the live link, then the jury may choose not to believe their version of events.

Other accommodations have not been subject to such extensive research, including the use of intermediaries for vulnerable witnesses. This may be due to the fact that the intermediary scheme is used in only a small number of countries and this development has occurred recently. The role of the intermediary is to facilitate communication between vulnerable witnesses and practitioners working in the criminal justice system (Ministry of Justice, 2015). In England and Wales intermediaries are trained and accredited by the Ministry of Justice and are called Registered Intermediaries (RIs). RIs perform a number of different tasks to assist the police during forensic interviews and other professionals in court (please refer to the Registered Intermediary Procedural Guidance Manual, Ministry of Justice, 2015, for a comprehensive overview of the role of RIs in England and Wales). RIs assess the vulnerable person's communication abilities, and afterwards write a full report providing recommendations for how to communicate and gain best evidence from the vulnerable person when they participate in criminal proceedings (Ministry of Justice, 2015). If the intermediary has accepted a referral for court then the recommendations outlined in the report are summarised to the judge and counsel in a 'ground rules hearing' prior to the commencement of the trial. At this point the judge decides which recommendations will be implemented during the proceedings. However, it is important to note the focus is on facilitating the communication of 'best evidence', not on assisting practitioners with the evidential content of their questions (Ministry of Justice, 2015). RIs act as officers of the court and must take a neutral stand in their approach to their work (Ministry of Justice, 2015).

After the ground rules hearing the intermediary is present to assist the vulnerable person, and the practitioner, when the vulnerable person is being questioned in court. During crossexamination they sit next to the witness and must be visible on camera or visible in the witness box. RIs are also permitted to intervene during cross examination, if the communication recommendations granted during the grounds rules hearing are not being adhered to, or they notice something about the vulnerable witness that may be affecting their ability to communicate effectively (e.g. if the witness is tired and needs a break).

The practice of intermediaries also varies dependent upon the country in which the scheme operates (Powell, Bowden, \& Mattison, 2014). In South Africa the intermediary acts like an interpreter by listening to the questions put forward by counsel and translating these into words that the vulnerable person will understand (Criminal Procedure Act, 1977). In Norway specialist child interviewers question children for prosecution and defence and this interview is video recorded and played later at trial (Hanna, Davies, Henderson, \& Hand, 
2013). In Israel a specially trained child interviewer also carries out a video recorded interview with the child. If the case proceeds to court then the interviewer can translate questions similar to the work of South African intermediaries (Henderson cited in Spencer \& Lamb, 2012).

The work of intermediaries has not been subject to extensive research. Plotnikoff and Woolfson (2007) conducted a major review of the new intermediary scheme in England and Wales when it was first implemented. One of the most prominent findings was that carers and witnesses felt RIs assisted their communication and helped them cope with the stress of providing testimony. Intermediary work in South Africa has been praised for maintaining the fairness of the South African justice system (Matthias \& Zeal, 2011). The idea of the intermediary scheme has not been as well received by some practitioners in Australia. Powell et al (2014) carried out interviews with criminal justice practitioners and asked their views on the benefits of introducing an intermediary scheme there. Whilst the practitioners could see the positive implications for vulnerable witnesses they discussed a number of concerns. These included adding a further complication to an already complex legal system, concerns over perceptions of the role, and questions about training and maintaining professional competency. In contrast, in their review of the support for individuals with learning difficulties in the Australian criminal justice system, Hepner, Woodward, and Stewart (2015) argue that the introduction of a witness intermediary scheme is essential to facilitate access to justice for vulnerable witnesses in Australia.

Ridley, van Rheede, and Wilcock (2015) investigated the impact of intermediary presence on mock juror, police officer and barristers' perceptions of a forensic interview between a police officer and a child. The participants read a written transcript with or without an intermediary present. In the intermediary present condition the intermediary intervened five times when the questions were not child appropriate. The interview quality was more positively perceived when the intermediary was present however intermediary presence had no impact on perceptions of the child. Furthermore, barristers tended to perceive the child more negatively than police officers or mock jurors, and police officers found the child more credible than barristers and mock jurors. However, the scope of the findings is limited as participants read a transcript instead of observing intermediary and child behaviour. Ordinarily barristers and jurors would watch a visual recording of the interview in court and this would permit access to the behaviour and tone of the child and intermediary, which may in turn result in different perceptions of the quality of the interview and credibility of the child.

In other research, concerns have been raised by intermediaries about the training of intermediaries who work with defendants (O'Mahony, 2010). In England and Wales statutory legislation covers the work of intermediaries with vulnerable witnesses but not defendants (Cooper \& Wurtzel, 2013). Intermediary practice with defendants operates under common law where the use of an intermediary for a defendant set the precedent for the use of defendant intermediaries in criminal courts (Cooper \& Wurtzel, 2013). However, the practice is not standardized, training is not accredited and there is no quality assurance. Registered intermediaries who have also worked with defendants have expressed concern about how they would be perceived by the jury when assisting a vulnerable defendant in court (O’Mahony, 2010).

Nevertheless, there has been no research on how intermediaries and vulnerable people are perceived when cross-examined in court. Unlike the South African scheme there is no empirical research to date that examines whether or not the involvement of the intermediary during cross-examination in court influences the jury and undermines the fairness of the criminal justice system. Given that the live link has been shown to affect jury perceptions of children then it is also important to examine whether the work of the intermediary in court has a positive or negative effect on the jury too. Negative perceptions may mean the jury has to be provided with more detailed instructions about the role of the RI in court. 
The present study investigated the impact of intermediary involvement on mock juror perceptions of children and their communication when they were cross-examined in court. Mock jurors watched a video clip of children being questioned either with or without an intermediary and rated the children on a number of different dimensions. The age of the child was also manipulated with participants viewing a clip of a 4 year-old child or a 13 yearold teenager. Juror perceptions of children can vary dependent upon the age of the child and we were interested to see whether this same effect occurred when an intermediary was present or absent. We expect that juror perceptions of the children's communication will be better when an intermediary is present, but that ratings of their credibility and believability will be lower as the juror's expectations are violated if the children's communication improves (McAuliff \& Kovera, 2012) when accompanied by the intermediary. We also predict the older child's communication and behaviour etc. will be scored higher than the younger child as previous research indicates a bias in favour of older child witnesses (e.g. Holcomb \& Jacquin, 2007; Nikanora \& Ogloff, 2005; Pozzulo et al., 2006).

\section{Methods and Data}

\section{Participants and Design}

The study involved 100 participants (35 males and 65 females) from an English University who were recruited using the University's online experiment sign up system. The mean age was 21 years with an age rage of 18 to 57 . All participants met the UK's jury eligibility criteria. Therefore all participants were aged between 18 and 70, listed on the electoral register and did not have any criminal convictions.

The study was separated into two parts - a recorded mock cross-examination and an evaluation of this cross-examination. For the first part the children watched a cartoon and were cross-examined about the content of the cartoon. In the second part of the study participants watched one of the cross-examinations and rated the children and the crossexamination on a number of different variables. The first independent variable (IV) was the involvement of an intermediary during cross-examination, with two levels: no intermediary present and intermediary present. The second IV was the age of the child witness with two levels: young child (four years old) and teenager (13 years old). Both IVs were independent measures and participants were randomly assigned to a condition.

In order to measure people's perceptions of the child witness, participants were asked to rate the following variables: truthfulness, credibility, believability, vulnerability, cooperativeness, responsiveness, comfortableness, confidence, consistency, accuracy, suggestibility and stress level. In order to measure people's perceptions of the cross examinations as a whole participants were asked to rate the following: child centeredness, child appropriateness, and the quality of the interaction. These variables were measured in the form of a questionnaire, which was constructed by the researchers, based on the most frequent variables used in other research to examine people's perceptions of children in forensic settings (e.g. Goodman et al., 1998; Holcomb \& Jacquin, 2007; Nikanora \& Ogloff, 2005; Pozzulo et al., 2006).

\section{Materials and Procedure \\ Mock cross-examinations.}

The researchers recorded four cross-examination video clips: young child without intermediary, young child with intermediary, teenager without intermediary and teenager with intermediary. Before producing the clips, parental consent was obtained for both children. In all four cross-examinations, there was a mock child witness, a mock barrister, and a mock judge. In addition to this, in two of the cross examinations, an intermediary was 
present and in the other two cross-examinations, a support worker was present (as in accordance with UK Achieving Best Evidence Guidance, Ministry of Justice, 2011). The support worker sat next to the child witness in the same position and place as the intermediary in the intermediary condition. The support worker did not intervene in the questioning between the barrister and the child witness.

The cross examinations took place in a mock courtroom at an English University, where the child witnesses were cross examined over live video link. As a result, the video recording shown to participants in the study included the barrister and the judge situated in the mock courtroom whilst questions were being asked, with the child witness visible on a TV screen, situated in a remote room.

Within all four cross-examinations the child witness was questioned by the barrister about the cartoon. Both child witnesses observed the cartoon together; however they were individually cross-examined. In order to alleviate practice effects the child witnesses observed two different cartoons before carrying out the two cross-examinations, with and without the intermediary. Firstly, the child witnesses observed cartoon one and were then questioned during the cross examination with the presence of a support worker. Following this, the child witnesses observed cartoon two and were then questioned with the presence of an intermediary. Both cartoons involved the animated characters Tom and Jerry. The decision was made to involve two cartoons as opposed to one, because there were concerns that practice effects may occur if the child witnesses were questioned about the content of a single cartoon twice (once with the intermediary present and once with the intermediary absent). For example, the child witnesses may have responded better when asked questions about the cartoon a second time, therefore possibly improving the participant's perception of the child's performance in that condition.

For the cross-examination with the presence of a support worker, both child witnesses were required to observe cartoon one, which lasted two minutes and forty-one seconds. During this cartoon, Tom was chasing Jerry and both were interrupting the dog whilst he built his kennel. The dog was very angry with this. For the cross-examination with the presence of an intermediary, both child witnesses were required to observe cartoon two which lasted two minutes and nineteen seconds. During this cartoon, Tom chased Jerry who was being protected by the dog. However, the dog is tied to his kennel and when Tom becomes aware of this, he starts teasing the dog with violence.

In the first condition (young child without intermediary), the cross examination lasted two minutes and forty-seven seconds. In the second condition (teenager without intermediary), the cross examination lasted one minute and forty-two seconds. In the third condition (young child with intermediary), the cross examination lasted four minutes and thirty-eight seconds. Lastly, in the fourth condition (teenager with intermediary), the cross examination lasted three minutes and forty-one seconds.

For all cross-examinations the barrister and the judge followed a script that was produced by the researchers, and a qualified registered intermediary reviewed the content. This intermediary is a psychologist who has fourteen years' worth of experience working with children. During the cross examinations, the intermediary intervened when inappropriate questions were asked. However, during the cross examinations without the intermediary, the cross examination was conducted with no interventions as there was no intermediary present. Overall, the questions asked by the barrister included five child appropriate questions and five child inappropriate questions. The researcher produced these questions based on guidance by the same RI who previously helped with the research. The selected questions included four different parts of questioning that often prove problematic for children during the course of questing in court: time concepts, long questions, leading questions, and tag questions (Lamb, La Rooy, Malloy, \& Katz, 2011). The questions asked across both factors were scripted and therefore were the same in all four conditions. In addition, the questions asked by the barrister for both cartoons were extremely similar. For example, the phrasing 
was the same for both cartoons, but the content was slightly different due to the different cartoons. As well as this, the same number of questions was used with both child witnesses, including the same number of appropriate and inappropriate questions. For example an appropriate question was 'please tell me everything you can remember about the cartoon?' and an example of an inappropriate question was 'so you remember the cat giving the mouse cheese, and then the cat reading the newspaper and walking out the room, can you remember what the cat did then?' This question was inappropriate because it was too complex and contained too many ideas. With the inappropriate questions the intermediary intervened with 'excuse me your honour, that question (for example) is too complex, please could counsel rephrase?' The judge then agreed and asked counsel to rephrase. Below is a list of all of the questions and interventions:

\section{Cross examination without intermediary.}

1. Please tell me everything you can remember about the cartoon? (appropriate)

2. So you can remember the dog hitting the cat over the head with a hammer? (inappropriate)

3. In the cartoon, can you remember if it was sunny, rainy or something else? (appropriate)

4. I want to know what time the events in the cartoon occurred, was it around 15.00 hours? (inappropriate)

5. What did the cat look like? (appropriate)

6. The cat is naughty in the cartoon isn't he? (inappropriate)

7. What was the mouse doing at the end of the cartoon? (appropriate)

8. So you can remember the dog hitting the cat with a hammer, then the dog building a house and painting the cat, can you remember what the dog did then? (inappropriate)

9. How did the dog feel at the end of the cartoon? (appropriate)

10. The dog painted his house red, didn't he? (inappropriate)

\section{Cross examination with intermediary.}

1. Please tell me everything you can remember about the cartoon? (appropriate)

2. So you can remember the dog hitting the cat over the head with his fist? (inappropriate)

3. In the cartoon, can you remember if it was sunny, rainy or something else? (appropriate)

4. I want to know what time the events in the cartoon occurred, was it around 13.00 hours? (inappropriate)

5. What did the mouse look like? (appropriate)

6. The mouse is naughty in the cartoon isn't he? (inappropriate)

7. What was the cat doing at the end of the cartoon? (appropriate)

8. So you can remember the cat giving the mouse cheese, and then the cat reading the newspaper and walking out the room, can you remember what the cat did then? (inappropriate)

9. How did the cat feel at the end of the cartoon? (appropriate)

10. The mouse rang the big bell didn't he? (inappropriate) 


\section{Interventions and rephrasing of the five inappropriate questions in the intermediary present condition.}

1. Intervention: Excuse me your honour, that question is leading, please could counsel rephrase? Rephrased question: Tell me more about what happened in the cartoon?

2. Intervention: Excuse me your honour, that question involves an understanding of the 24 hour clock and it is long and complicated, please could counsel rephrase?

Rephrased question: In the cartoon, was it day time or night time?

3. Intervention: Excuse me your honour, that question has a tag at the end, please could counsel rephrase? Rephrased question: was the mouse naughty?

4. Intervention: Excuse me your honour, that question is too complex, please could counsel rephrase? Rephrased question: so the cat read the newspaper and walked out of the room (pause) what happened next?

5. Intervention: Excuse me your honour, that question has a tag at the end, please could counsel rephrase? Rephrased question: did the mouse ring the bell?

\section{Written resources for participants.}

Participants read one of two case summaries. The case summary included information about the cartoon the child witnesses observed. The information included what time of the day the cartoon was filmed, what the characters in the cartoon were accused of doing and the location presented in the cartoon. They were also informed about the role of the intermediary (if in the intermediary present condition) and the support person. The instructions were in accordance with the Crown Court bench book's information on how the judge instructs the jury about the role of the intermediary (Judicial Studies Board, 2010). Therefore the adults were informed that the intermediary was not an expert, was independent, was present to assist with two-way communication, and would only intervene if a communication problem were identified (Judicial Studies Board, 2010). After reading the case summary, the participants watched one of the four cross-examinations on a computer. Participants then completed the questionnaire about their perceptions of the child witness and the cross-examination. They were required to score the 16 variables (listed above) on a five point likert scale ranging from 1 (not very) to 5 (extremely).

\section{Results}

Before analysing the data, the 16 variables were separated into two groups: perception of the child witness's behaviour, and perception of the overall quality of cross-examination. To examine people's perception of the child witness's behaviour, the following variables were analysed: truthfulness, credibility, believability, vulnerability, cooperativeness, responsiveness, comfortableness, confidence, consistency, accuracy, suggestibility and stress level. To examine people's perception of the overall quality of cross-examination, the following variables were analysed: child centeredness, child appropriateness, and interaction. A two way MANOVA was used to analyse the impact of intermediary presence, and child's age on adult's perceptions.

\section{Perceptions of the Child Witness's Communication and Behaviour}

The analysis revealed a significant multivariate effect for intermediary presence, Wilks' $\lambda$ $=.61, F(12,85)=4.54, p<.001, n p^{2}=.39$. Given the significance of the overall MANOVA test, the univariate main effects for intermediary presence were obtained. Intermediary presence was highly significant for truthfulness, with children in the intermediary present 
condition being rated as more truthful than children without an intermediary, $F(1,96)=$ $16.49, p<.001, n p^{2}=.15$. Intermediary presence was also highly significant for credibility, $F$ $(1,96)=20.46, p<.001, n p^{2}=.18$ with participants rating the child as more credible with the presence of an intermediary. Believability was again highly significant for intermediary presence, $F(1,96)=25.88, p<.001, n p^{2}=.21$ as well as vulnerability, $F(1,96)=13.55, p<$ $.001, n p^{2}=.12$. Children were perceived as more believable and less vulnerable with the presence of an intermediary.

As well as this, children were perceived as being significantly more cooperative with the presence of an intermediary, $F(1,96)=9.93, p=.002, n p^{2}=.09$ and more responsive with the presence of an intermediary, $F(1,96)=10.20, p=.002, n p^{2}=.10$. In addition to this, intermediary presence was significant for how comfortable the child seemed, $F(1,96)=$ 4.78, $p=.03, n p^{2}=.05$ and confident, $F(1,96)=11.43, p<.001, n p^{2}=.11$. Therefore, children were perceived as more comfortable and confident with the presence of an intermediary. Children, with the presence of an intermediary, were also perceived as more consistent, $F(1,96)=25.24, p<.001, n p^{2}=.21$ and accurate, $F(1,96)=17.75, p<.001, n p^{2}$ $=.16$. Lastly, children in the intermediary present condition were rated as less suggestible than children without an intermediary, $F(1,96)=40.85, p<.001, n p^{2}=.30$ and less stressed, $F(1,96)=4.80, p=.03, n p^{2}=.05$.

The analysis revealed there was not a significant multivariate effect for age, Wilks' $\lambda=$ $.82, F(12,85)=1.55, p>.05, n p^{2}=.18$. The analysis revealed there was no significant interaction between intermediary presence and age, Wilks' $\lambda=.84, F(12,85)=1.38, p>.05$, $n p^{2}=.16$. Please refer to table 1 for all means and standard deviations.

\section{Insert table 1 here please}

\section{Perceptions of the Quality of the Cross Examination}

The analysis revealed a significant multivariate effect for intermediary presence, Wilks' $\lambda$ $=.88, F(4,93)=3.19, p=.02, n p^{2}=.12$. Given the significance of the overall MANOVA test, the univariate main effects for intermediary presence were obtained. Intermediary presence was significant for child centeredness, with the cross examination being perceived as more child centred with the presence of an intermediary, $F(1,96)=5.29, p=.02, n p^{2}=$ .05 . The cross examination was also perceived as significantly more child appropriate with the presence of an intermediary, $F(1,96)=8.12, p=.01, n p^{2}=.08$. In the intermediary present condition, the participants perceived the interaction between the child witness and the barrister to be better, compared to the cross examination without an intermediary, $F(1,96)=$ $6.65, p=.01, n p^{2}=.07$.

The analysis revealed a significant multivariate effect for age, Wilks' $\lambda=.87, F(4,93)=$ $3.53, p=.01, n p^{2}=.13$. Given the significance of the overall MANOVA test, the univariate main effects for age were obtained. Age was significant for child appropriateness, with the cross examination being perceived as more child appropriate with the teenager, $F(1,96)=$ 9.13, $p=.003, n p^{2}=.09$. However, there was no significant effect for child centeredness, $F$ $(1,96)=1.42, p>.05, n p^{2}=.02$, as well as the quality of the interaction during crossexamination, $F(1,96)=.63, p>.05, n p^{2}=.01$. The analysis revealed there was no interaction between intermediary presence and age, Wilks' $\lambda=.97, F(4,93)=.78, p>.05$, $n p^{2}=.03$. Please refer to Table 2 for all means and standard deviations.

\section{Insert table 2 here please}

\section{Discussion}

As predicted the ratings for children's communication and the quality of the crossexamination were greater in the intermediary 'present' versus 'not present' conditions. Therefore, this special measure does not have a detrimental impact on adult perceptions of 
children's communication, behaviour and the quality of the cross-examination. Previous research on other accommodations, e.g. the live link (e.g. Landstrom \& Granhag, 2007, 2010), has often been found to have negative implications for juror perceptions. The intermediary's involvement does not have the same effect.

With regards to the children's communication and behaviour it is possible that the adult ratings were correct and the children were less anxious, stressed, suggestible, and more comfortable, confident, consistent and accurate when the intermediary was involved. Previous research indicates that adult support reduces children's anxiety and suggestibility, and increases their accuracy and coherence (e.g. Almerigogna, Ost, Bull, \& Akehurst, 2007). In the intermediary present condition the intermediary actively intervened and assisted the child in providing their best evidence. However, a comparison of the children's recall was not made across conditions, as not enough children were involved and this was not the purpose of the present study. It is imperative that future research compares children's communication when an intermediary is involved and examines the relationship between the children's communication and mock juror perceptions. This would support the interpretation that intermediaries help children improve their communication and that jurors detect this improvement.

Also consistent with our predictions was the finding that the cross-examination was rated better on all three dimensions when the intermediary was involved. This supports Ridley et al's (2015) finding that interview practice is more positively evaluated when an intermediary is present during questioning. In our intermediary present condition the intermediary regularly intervened when an inappropriate question was asked during cross-examination. During these interventions the mock jury could hear the intermediary make clear statements about what was wrong with the questioning, the judge's instructions to modify the questions and the rephrasing of the questions by counsel. Therefore it is not surprising that the crossexaminations in this condition were rated as more child centred and appropriate. This finding shows that the intermediary special measure improves the mock juror's perception of the cross-examination. When an intermediary assists a vulnerable witness in court their recommendations apply to both prosecution and defence so the interventions should not offer any bias in favour of one side or the other. However, in this study the jury did not know whether or not the mock barrister was on the side of the prosecution or defence. It would be interesting to examine whether or not intermediary presence and intervention interacts with the side in which the child witness is called for.

Contrary to our predictions, intermediary involvement did not reduce participants' ratings of children's credibility and believability. Based on McAuliff and Kovera's (2012) expectancy violation theory we hypothesized that the ratings for both of these measures would be lower when the intermediary was involved, as adults would expect the children's communication to have been negatively affected by the experience of cross-examination. Therefore, when the children's communication was not adversely affected then jurors would become suspicious of the validity of the account (McAuliff \& Kovera, 2012). This theory has been used to explain why adult participants often rate children as less credible etc. when they communicate via live link versus in open court. Children's recall and behaviour is improved as a result of the live link (Landstrom \& Granhag, 2010; Goodman et al., 1998; Wilson \& Davies, 1999) but because this violates juror expectations then a reduction in credibility and believability may be found. This effect did not occur in the present study. We propose that differences in findings between the intermediary special measure and the live link research may be due to the immediacy of the intermediary accommodation. The mock judge explained to the participants that the purpose of the intermediary was to assist the vulnerable witness with their communication. Therefore the reasons for any improvement in communication can be justified by the intermediary's involvement. Future research should examine the effects of the intermediary with and without judicial instructions to support this explanation. 
In contrast, Ridley et al (2015) found no effect for intermediary presence on the perceptions of children in a mock investigative interview. In their discussion the authors highlight that their materials lacked ecological validity as they used a written transcript and visual or audio recordings would have been preferable. The current study used a visual recording of a mock cross examination and it is possible that access to the child's demeanour and non-verbal communication produced the different finding. In criminal courts jurors would have visual access to this information and arguably our research findings produce a more valid effect.

On all dimensions intermediary involvement improved adult perceptions of children's communication and the quality of the mock cross-examination. Therefore in court this special measure may not have a negative effect on juror perceptions of children's testimony. Nevertheless, for ethical reasons we were unable to investigate the impact of the intermediary on verdict. We asked the children to watch a cartoon as opposed to exposing them to a criminal event and therefore exploration of the impact of the intermediary on verdict was not possible. The witness intermediary scheme aims to facilitate the communication of children's best evidence, but intermediaries are officers of the court and maintain a neutral position (Ministry of Justice, 2015). The scheme was not designed to deliver an unfair advantage to vulnerable individuals and interfere with the fairness of the justice system. Further research is required to explore the effects of the intermediary on jury deliberations and verdicts as well. If intermediary involvement has no effect on verdict then the effectiveness and neutrality of the intermediary scheme can be fully supported.

As predicted, the intermediary condition improved adults' perceptions regardless of the age of the child. This demonstrates that the intermediary accommodation has benefits with regards to adult observations for both younger children and teenagers. Younger children in particular are often discriminated against by jurors and rated as less credible and believable than older children and adults (Holcomb \& Jacquin, 2007; Nikanora \& Ogloff, 2005; Pozzulo et al., 2006). However, no age effect was found in the present study across all of the measures, except adult perceptions of how child appropriate the cross-examination was. This variable was rated higher with the teenager than the younger child. Perhaps jurors recognize that cross-examination is a difficult procedure for vulnerable witnesses with regards to communication and questioning and the process and language is better suited to older children than younger children.

This study advances our understanding of adult perceptions of children's communication and cross-examination when accompanied by an intermediary. However, the findings have to be interpreted with regards to the study's limitations and further examination is required. Future research should create a paradigm where it is possible to explore the effects of intermediary presence on verdict and where a process of deliberation is used to decide on a verdict. If results were the same this would add to the validity of the findings. It is also important that empirical data is collected to demonstrate the influence of the intermediary on children's recall and communication. As yet, we do not know whether the scheme has any benefit for the elicitation of best evidence in the police interview or at court. It would also be interesting to ask the mock jurors what they thought about the work of the intermediary and whether they understood the role. This would further explain why they rated the children's communication and the quality of the cross-examination as better when the intermediary was involved.

At this point in time, it is not clear what underpins the improvements in perceptions. Whether it is the presence of the intermediary or the use of more developmentally appropriate questions and therefore clearer answers from the children. We had a condition involving the presence of a support person to rule out the possibility that the adult's presence may influence perceptions. However, it would now be useful to carry out further research where the children are asked questions with or without an adult or intermediary present and where questions are or are not developmentally appropriate. This research would help in further 
understanding the psychological mechanisms behind the improvements in mock juror perceptions with intermediary work, and possibly lend further support to the theory that it is the intermediary's involvement that produces these differences.

Finally, when the children were questioned with the intermediary's involvement they had already been questioned without the intermediary and therefore may have been more comfortable communicating in the intermediary condition due to a slight increase in familiarisation with the process. However, comparison of the content of the children's recall was not the purpose of the study, and the children were questioned about a different cartoon across conditions to reduce the effects of practice on recall.

For the time being, the witness intermediary scheme continues to be endorsed by carers, witnesses and practitioners as an effective procedure for the facilitation of children's best evidence. The current study demonstrates intermediary assistance improves adult perceptions of children's testimony, and the process of cross-examination, regardless of age. Jury deliberation is the final stage in the long process of the prosecution of criminal behaviour, therefore it is essential to examine whether or not the intermediary accommodation can enhance the fairness of the process for vulnerable witnesses without jeopardizing the rights of the defendant.

\section{References}

Almerigogna, J., Ost, J., Bull, R., \& Akehurst, L. (2007). A state of high anxiety: How nonsupportive interviewers can increase the suggestibility of child witnesses. Applied Cognitive Psychology, 21, 963-974. doi: 10.1002/acp.1311

Berman, G. L., \& Cutler, B. L. (1996). Effects of inconsistencies in eyewitness testimony on mock-juror decision making. Journal of Applied Psychology, 81, 170-177. doi: 10.1037/0021-9010.81.2.170

Cooper, P., \& Wurzel, D. (2013). A day late and a dollar short: In search of an intermediary scheme for vulnerable defendants in England and Wales. Criminal Law Review, 1, 422.

Cossins, A. (2006). Prosecuting child sexual assault cases: Are vulnerable witness protections enough? Current Issues in Criminal Justice, 18, 299-317.

Criminal Procedure Act. (1977). (South Africa) s170A.

Davies, E., Devere, H., \& Verbitsky, J. (2004). Court education for young witnesses: Evaluation of the pilot service in Aotearoa, New Zealand. Psychiatry, Psychology and Law, 11, 226-235. doi: 10.1375/pplt.2004.11.2.226

Davies, E., Henderson, E., \& Hanna, K. (2010). Facilitating children to give best evidence: Are there better ways to challenge children's testimony. Criminal Law Journal, 34, 347-362.

Doherty-Sneddon, G., \& McAuley, S. (2000). Influence of video-mediation on adult-child interviews: Implications for the use of the live link with child witnesses. Applied Cognitive Psychology, 14, 379-392.

Eaton, T. E., Ball, P. J., \& O'Callaghan, G. (2001). Child-witness and defendant credibility: Child evidence presentation mode and judicial instructions. Journal of Applied Psychology, 31, 1845-1858. doi: 10.1111/j.1559-1816.2001.tb00207.x

Goodman, G. S., Tobey, A. E., Batterman-Faunce, J. M., Orcutt, H., Thomas, S., Shapiro, C., \& Sachsenmaier, T. (1998). Face-to-face confrontation: Effects of closed-circuit technology on children's eyewitness testimony and jurors' decisions. Law and Human Behavior, 22, 165-203.

Hamlyn, B., Phelps, A., Turtle, J., \& Sattar, G. (2004). Are special measures working? Evidence from surveys of vulnerable and intimidated witnesses (Home Office Research Study 283). London: Home Office. 
Hanna, K., Davies, E., Henderson, E., \& Hand, L. (2013). Questioning child witnesses: Exploring the benefits and risks of intermediary models in New Zealand. Psychiatry, Psychology and Law, 20, 527-542. doi: 10.1080/13218719.2012.726148

Henry, L., Ridley, A., Perry, J., \& Crane, L. (2011). Perceived credibility and eyewitness testimony of children with intellectual disabilities. Journal of Intellectual Disability Research, 55, 385-391. doi: 10.1111/j.1365-2788.2011.01383.x

Hepner, I., Woodward, M.N., \& Stewart, J. (2015). Giving the vulnerable a voice in the criminal justice system: The use of intermediaries with individuals with intellectual disability. Psychiatry, Psychology, \& Law, 22, 453-464. doi: 10.1080/13218719.2014.960032

Holcomb, M. J., \& Jacquin, K. M. (2007). Juror perceptions of child eyewitness testimony in a sexual abuse trial. Journal of Child Sexual Abuse, 16, 79-95.

Lamb, M.E., La Rooy, D.J., Malloy, L.C., \& Katz, C. (2011). Children's Testimony: A Handbook of Psychological Research and Forensic Practice (2nd Edition). West Sussex: Wiley-Blackwell.

Landstrom, S., \& Granhag, P. A. (2010). In-Court versus out-of-court testimonies: Children's experiences and adults' assessments. Applied Cognitive Psychology, 24, 941-955. doi: 10.1002/acp.1606

Landstrom, S., Granhag, P. A., \& Hartwig, M. (2007). Children's live and videotapes testimonies: How presentation mode affects observers' perception, assessment and memory. Legal and Criminological Psychology, 12, 333-347.

Matthias, C. R., \& Zaal, F. N. (2011). Intermediaries for child witnesses: Old problems, new solutions and judicial differences in South Africa. International Journal of Children's Rights, 19, 251-269. doi: 10.1163/157181810x527987

McAuliff, B. D., \& Kovera, M. B. (2012). Do jurors get what they expect? Traditional versus alternative forms of children's testimony. Psychology, Crime \& Law, 18(1), 27-47. doi: 10.1080/1068316x.2011.613391

Ministry of Justice. (2011). Achieving Best Evidence in Criminal Proceedings. London: Ministry of Justice.

Ministry of Justice. (2015). The registered intermediary procedural guidance manual. London: Ministry of Justice.

Nikonova, O., \& Ogloff, J. R. P. (2005). Mock jurors' perceptions of child witnesses: The impact of judicial warning. Canadian Journal of Behavioural Science, 37, 1-19. doi: $10.1037 /$ hoo 87241

O'Mahony, B. M. (2010). The emerging role of the Registered Intermediary with the vulnerable witness and offender: facilitating communication with the police and members of the judiciary. British Journal of Learning Disabilities, 38, 232-237.

Orcutt, H. K., Goodman, G. S., Tobey, A. E., Batterman-Faunce, J. M., \& Thomas, S. (2001). Detecting deception in children's testimony: Fact finders' abilities to reach the truth in open court and closed-circuit trials. Law and Human Behavior, 25, 339-372. doi: 10.1023/A:1010603618330

Plotnikoff, J., \& Woolfson, R. (2007). The 'Go-Between': Evaluation of Intermediary Pathfinder Projects. London, Ministry of Justice.

Powell, M. (2005). Improving the reliability of child witness testimony in court: The importance of focusing on questioning techniques. Current Issues in Criminal Justice, 17, 137-143.

Powell, M.B., Bowden, P., \& Mattison, M. (2014). Stakeholder's perceptions of the benefit of introducing an Australian intermediary system for vulnerable witnesses. Australian \& New Zealand Journal of Criminology, 0, 1-15. doi: 10.1177/00048658/4543391

Pozzulo, J. D., Lemieux, J. M. T., Wells, E., \& McCuaig, H. J. (2006). The influence of eyewitness identification decisions and age of witness on jurors' verdicts and 
perceptions of reliability. Psychology, Crime \& Law, 12, 641-652. doi: 10.1080/10683160500415539

Quas, J. A., Thompson, W. C., \& Clarke-Stewart, K. A. (2005). Do jurors "know" what isn't so about child witnesses? Law and Human Behavior, 29, 425-456.

Righarts, S., Jack, F., Zajac, R., \& Hayne, H. (2015). Young children's responses to crossexamination style questioning: The effects of delay and subsequent questioning. Psychology, Crime \& Law, 21, 274-296. doi: 10.1080/1068316x.2014.951650

Ridley, A.M., van Rheede, V., \& Wilcock, R. (2015). Interviews, intermediaries and interventions: mock jurors', police officers' and barristers' perceptions of a child witness interview. Investigative Interviewing: Research and Practice, 7, 21-35.

Ross, D. F., Hopkins, S., Hanson, E., Lindsay, R. C. L., Hazen, K., \& Eslinger, T. (1994). The impact of protective shields and videotape testimony on conviction rates in a simulated trial of child sexual abuse. Law and Human Behavior, 18, 553-566.

Smith, K. (2015, January 7-8). Special measures professional training \& development seminar. Paper presented at The Special Measures Seminar, National Crime Agency, Wyboston Lakes, England.

Spencer, J., \& Lamb, M. (2012). Children and cross-examination: Time to change the rules? United Kingdom: Hart Publishing.

Sumner-Armstrong, C., \& Newcombe, P. A. (2007). The education of jury members: Influences on the determinations of child witnesses. Psychology, Crime \& Law, 13, 229-244. doi: 10.1080/10683160600821925

Wilson, J. C., \& Davies, G. M. (1999). An evaluation of the use of videotaped evidence for juvenile witnesses in criminal courts in England and Wales. European Journal on Criminal Policy and Research, 7, 81-96. doi: 10.1023/A: 1008740231642

Youth Justice and Criminal Evidence Act. (1999). (UK) s. 29. 
Table 1

Means and Standard Deviations for Adults' Perceptions of the Children's Communication and Behaviour Across Intermediary Presence and Age

\begin{tabular}{|c|c|c|c|c|c|c|}
\hline & \multicolumn{2}{|c|}{ Intermediary } & \multicolumn{2}{|c|}{ No Intermediary } & \multicolumn{2}{|l|}{ Total } \\
\hline & Child & Teenager & Child & Teenager & Child & $\underline{\text { Teenager }}$ \\
\hline \multirow{2}{*}{ Truthfulness } & 4.04 & 4.00 & 3.16 & 3.36 & 3.60 & 3.68 \\
\hline & $(0.93)$ & $(0.96)$ & (1.07) & $(0.76)$ & (1.09) & $(0.91)$ \\
\hline \multirow[t]{2}{*}{ Credibility } & 3.20 & 3.36 & 2.04 & 2.44 & 2.62 & 2.90 \\
\hline & (1.12) & $(1.32)$ & $(1.21)$ & $(0.92)$ & $(1.29)$ & $(1.22)$ \\
\hline \multirow[t]{2}{*}{ Believability } & 3.68 & 3.68 & 2.48 & 2.72 & 3.08 & 3.20 \\
\hline & (1.14) & (1.03) & (1.12) & $(0.94)$ & $(1.28)$ & (1.09) \\
\hline \multirow{2}{*}{ Vulnerability } & 3.24 & 3.24 & 2.28 & 2.36 & 2.76 & 2.80 \\
\hline & (1.42) & $(1.30)$ & $(1.28)$ & $(0.95)$ & $(1.42)$ & $(1.21)$ \\
\hline \multirow[t]{2}{*}{ Cooperativeness } & 4.20 & 4.32 & 3.48 & 3.84 & 3.84 & 4.08 \\
\hline & $(0.87)$ & $(0.69)$ & (1.16) & (1.03) & (1.08) & $(0.90)$ \\
\hline \multirow[t]{2}{*}{ Responsive } & 3.40 & 4.16 & 3.16 & 3.28 & 3.28 & 3.72 \\
\hline & $(0.76)$ & $(0.80)$ & $(0.99)$ & $(0.94)$ & $(0.88)$ & $(0.97)$ \\
\hline \multirow[t]{2}{*}{ Comfortable } & 3.12 & 3.08 & 2.80 & 2.56 & 2.96 & 2.82 \\
\hline & $(1.05)$ & (1.08) & $(0.87)$ & $(0.87)$ & $(0.97)$ & $(0.98)$ \\
\hline \multirow[t]{2}{*}{ Confidence } & 3.00 & 2.96 & 2.28 & 2.40 & 2.64 & 2.68 \\
\hline & $(0.96)$ & $(0.89)$ & $(0.94)$ & $(1.00)$ & $(1.01)$ & $(0.98)$ \\
\hline \multirow[t]{2}{*}{ Consistency } & 3.36 & 3.44 & 2.20 & 2.76 & 2.78 & 3.10 \\
\hline & $(0.76)$ & (1.04) & $(0.87)$ & $(0.97)$ & $(1.00)$ & $(1.05)$ \\
\hline \multirow[t]{2}{*}{ Accuracy } & 2.80 & 3.24 & 2.16 & 2.44 & 2.48 & 2.84 \\
\hline & $(0.96)$ & $(0.83)$ & $(0.85)$ & $(0.77)$ & $(0.95)$ & $(0.89)$ \\
\hline \multirow[t]{2}{*}{ Suggestibility } & 3.36 & 3.68 & 1.72 & 2.48 & 2.54 & 3.08 \\
\hline & $(1.25)$ & (1.14) & $(0.89)$ & (1.12) & (1.36) & $(1.28)$ \\
\hline \multirow[t]{2}{*}{ Stress level } & 4.00 & 3.76 & 3.56 & 3.28 & 3.78 & 3.52 \\
\hline & (1.04) & (1.01) & (1.12) & $(1.02)$ & (1.09) & (1.03) \\
\hline
\end{tabular}

Note. Standard deviations are in brackets. 
Table 2

Means and Standard Deviations for Adults' Perceptions of the Cross-examinations Across Intermediary Presence and Age

\begin{tabular}{|c|c|c|c|c|c|c|}
\hline & \multicolumn{2}{|c|}{ Intermediary } & \multicolumn{2}{|c|}{ No Intermediary } & \multicolumn{2}{|l|}{ Total } \\
\hline & Child & Teenager & Child & Teenager & Child & $\underline{\text { Teenager }}$ \\
\hline Child Centred & $\begin{array}{l}2.96 \\
(1.27)\end{array}$ & $\begin{array}{l}3.40 \\
(1.12)\end{array}$ & $\begin{array}{l}\overline{2.52} \\
(1.39)\end{array}$ & $\begin{array}{l}2.68 \\
(1.25)\end{array}$ & $\begin{array}{l}\overline{2.74} \\
(1.34)\end{array}$ & $\begin{array}{l}3.04 \\
(1.23)\end{array}$ \\
\hline Child Appropriate & $\begin{array}{l}2.84 \\
(1.14)\end{array}$ & $\begin{array}{l}3.72 \\
(1.02)\end{array}$ & $\begin{array}{l}2.36 \\
(1.22)\end{array}$ & $\begin{array}{l}2.88 \\
(1.24)\end{array}$ & $\begin{array}{l}2.60 \\
(1.20)\end{array}$ & $\begin{array}{l}3.30 \\
(1.20)\end{array}$ \\
\hline Interaction & $\begin{array}{l}3.28 \\
(1.14)\end{array}$ & $\begin{array}{l}3.24 \\
(1.01)\end{array}$ & $\begin{array}{l}2.56 \\
(0.77)\end{array}$ & $\begin{array}{l}2.92 \\
(1.08)\end{array}$ & $\begin{array}{l}2.92 \\
(1.03)\end{array}$ & $\begin{array}{l}3.08 \\
(1.05)\end{array}$ \\
\hline
\end{tabular}

Note. Standard deviations are in brackets. 